\title{
Role of Androgen on Physiological Function of Pilosebaceous Unit
}

\section{Inda Astri Aryani ${ }^{*}$, Cayadi Sidarta Antonius ${ }^{1}$, Suroso Adi Nugroho ${ }^{1}$, Nopriyati ${ }^{1}$}

${ }^{1}$ Department of Dermatology and Venereology, Faculty of Medicine Universitas Sriwijaya, Palembang. Indonesia.

\section{A R T I C L E I N F O Keywords: \\ Androgen \\ Pilosebaceous Unit \\ Physiological \\ *Corresponding author: \\ Inda Astri Aryani \\ E-mail address: \\ indaastri70@gmail.com}

All authors have reviewed and approved

the final version of the manuscript.

\begin{abstract}
A B S T R A C T
The pilosebaceous unit is a sebaceous gland with hair follicles. One of the hormones that affects the pilosebaceous unit is androgen, a steroid hormone that plays an important role in the expression of the phenotype of men and women. Androgen consist of testosterone and dihydrotestosterone which are activated by androgen receptors. Androgen in the pilosebaceous unit affect sebum production and hair growth. Androgen receptors in the sebaceous glands are found on sebocytes and in hair follicles in the dermal papillae of hair follicles
\end{abstract}

https://doi.org/10.32539/bsm.v5i6.321

\section{Introduction}

Skin is the largest organ in human, it is about 1.75 $\mathrm{m}^{2}$ in wide, and consists of various adnexal structures, such as hair follicle, nail, and glands. Sebaceous glands, a multilocular structure with connecting channels to excretory duct and connected to hair follicle. The size of sebaceous glands varies, even in the same anatomical area on one person. Sebaceous glands connected to hair is called pilosebaceous unit. ${ }^{1}$

Androgen, an endocrine hormone, plays major role in pilosebaceous unit is androgen. Androgen in hair follicle has a role to stimulate hair growth, and the in sebaceous glands is to stimulate production of sebum.2,3 Androgen synthesized in the gonad, adrenals, and skin. The major active androgens in pilosebaceous unit are testosterone and dihydrotestosterone. It was synthesized from cholesterol in pilosebaceous unit and mediated by several enzymes such as 5a-reductase, steroid sulfatase, and $17 \beta$-hydroxysteroid dehydrogenases. ${ }^{4}$

This literature review discusses the pilosebaceous unit, androgens, androgen receptors and the influence of androgens on the pilosebaceous unit. The aim of this review is to understand the role of androgen on the physiological function of the skin, especially the pilosebaceous unit.

\section{Androgen hormones}

Androgens synthesized in the gonads, adrenal glands, and skin. The production of androgen in gonad begins with neuronal release from brain to hypothalamus, then thalamus releases gonadotropinreleasing hormone (GnRH) to portal vein in pituitary. Gonadotropin-releasing hormone stimulate the 
pituitary to secrete luteinizing hormone (LH) and follicle stimulating hormone (FSH). Luteinizing hormone will stimulate interstitial cell, Theca cell in ovary and Leydig cell in testis to secrete androgen (Figure 1). ${ }^{5}$ At 6 weeks of gestation, Leydig cells in the testis will synthesize testosterones. Testosterones is the most circulated androgens, while 5a-dihydrotestosterones is the result of testosterone metabolism. ${ }^{6}$

There are several active androgens circulated in the blood, such as dehydroepiandrosterone sulfate (DHEAS), androstenedione, testosterone, and 5adihydrotestosterone (Table 1). Both DHEA-S and androstenedione were synthesized on the adrenal glands while both testosterone and 5a-DHT were synthesized on the gonads. Later, these androgens reach the skin via the bloodstream. ${ }^{6}$

In female, androgen production is produced by ovarium with stimulation of hypothalamus. Hypothalamus will release gonadotropin-releasing hormone and stimulate anterior pituitary to release luteinizing hormone $(\mathrm{LH})$ and follicle stimulating hormone (FSH). Later, LH will stimulate Theca cells in ovarium and transform cholesterol become androstenedione and testosterone. Some androstenedione and testosterone will enter circulatory bloodstream while other will be transformed into estrogen in ovarian granulosa cells. Testosterone is 10 times lower in female than male. ${ }^{7}$

Apart being produced by gonad cells, androgens also produced in the adrenal glands in form dehydroepiandrosterone-androgen (DHEA) and androstenedione stimulated by adrenocorticotropin hormone. With the addition of sulphate, dehydroepiandrosterone-androgen become DHEAsulphate (DHEA-S); becoming the reservoir for DHEA and other androgens. DHEA-sulphate has a longer lifetime than DHEA. 8

In the skin, androgen production is independent to hypothalamus control. Skin produces testosterone and DHT from circulated DHEA-S. The hair follicle papillae and sebaceous gland on the skin contain $3 \beta-$ hydroxysteroid dehydrogenase and $17 \beta$-hydroxysteroid dehydrogenase enzymes and involve in synthesis of testosterone (Table 2). 5a-reductase enzymes will convert testosterone to become DHT and it has 2 isoenzymes (type I and type II). 5a-reductase type I can be found in sebocytes, especially face sebocytes, sweats glands, keratinocytes, and dermal fibroblast. 5areductase type II can also be found in hair follicle. Androgen production in the skin also significantly contributes to the circulated androgen and systemically impactful.7,6,9,10

\section{The role of androgen in the pilosebaceous unit The role of androgen in hair follicles}

Hair follicles divided into three types: lanugo, vellus and terminal (Table 3). Lanugo is prenatal hair. Terminal hair is found on scalp, eyebrows, eyelashes at birth. During puberty, vellus is found on genitalia, axilla, trunk, and beard in men. Vellus will turn into terminal hair follicle under influence of androgen. ${ }^{3}$ There are 3 phases of hair follicle growth, named anagen, catagen and telogen phase. Some researchers also found another phase, called exogenous phase. The longest phase is anagen or growth phase, about 2-7 years. ${ }^{11}$

Androgens in form of testosterones and 5a-DHTs are activated after the binding to its receptors. Androgen receptors in pilosebaceous unit is found in keratinocytes, sebocytes, and papillae dermis cells. 6,10,12 Testosterones and 5a-DHTs will diffuse from blood to cell membrane and binds to androgen receptors in nucleus (Figure 2). ${ }^{13}$

The hair growth is influenced by the interaction of androgen with androgen receptors in dermal papillae. The synthesis of testosterones occurs in the mitochondria of target cells such as pilosebaceous unit in dermal papillae. After reaching the target cells, cholesterols are broken down under the influence of specific enzymes. ${ }^{14,15}$ Testosterones is converted into 5a-DHTs by type 2 5a-reductase enzyme during catalyzation. Later, androgens will stimulate the growth of hair follicles in specific area especially those related to secondary sexual characteristics, such as axillary hair, pubic hair and beard.6,10,13,16 Thera are 3 isoforms of 5a-reductase enzyme, namely type $15 a$-reductase, 
mostly found in hair and type 25 a-reductase and type 3 5a-reductase, mostly found in prostate and epididymis. ${ }^{8,16}$ (Table 3)

There is a hypothesis that androgen from circulating blood will enter the hair follicles through papillae dermis bloodstreams. Later, androgens will bind to androgen receptors and will be metabolized into 5aDHTs. When androgen binds to androgen receptor in dermal papillae cells, this will change the production of paracrine regulating factors and influencing the activities of papilla cells of dermal follicles ${ }^{13}$ (Figure 3)

During and after puberty, androgens will stimulate the development of small and colorless follicles of vellus into terminal follicle. Androgens, especially testosterones will influence the size of dermal papillae until the proportion of hair and follicles is reached. This change is consistent with hair cycle. Testosterone will stimulate follicles to produce vellus hair which is colorless in many parts of body and changes it into big hair follicle and produce longer, thicker and more pigmented hair. This process will make a more visible hair in many parts of body. ${ }^{13}$

In baldness or hair loss, 5a-DHTs stimulate big hair follicle into smaller vellus follicles and produce smaller and colorless hair. In androgenic alopecia, testosterone will be metabolized into 5a-DHTs. If testosterones and $5 a-D H T s$ are available in same amount, receptor will bind to 5a-DHTs and cause miniaturization of hair follicles. 13

\section{The role of androgen in sebaceous glands}

Sebaceous glands produce sebum that will coat hair and secreted along the hair shaft to skin surface. the function of sebum is as a hydrophobic coating to reduce trans epidermal water loss (TEWL) and to maintain skin hidration. 18

Dehydroepiandrosterone sulphate is the highest androgen hormone in terms of concentration in male and female and considered as the regulating factor in sebum secretion. Dehydroepiandrosterone sulphate (DHEA-S) is weak androgen in sebocytes and dermal papilla cells. Both sebocytes and dermal papilla cells have enzyme that change DHEA-Ss and androstenediones into stronger androgens such as testosterones and DHTs. Both androstenediones and testosterones also have been proven to stimulate secretion of human sebum. ${ }^{6}$

Sebum production of sebaceous glands is affected by androgen level, stronger androgen stimulation, and their binding to androgen receptors. Androgen receptors can be found in basal layers of sebaceous glands. Sebum production is significantly higher in first day of birth in both sexes and persisted until the second months. This condition is found to be related to genitalia crisis. Genitalia crisis is characterized by breast swelling, edema genitalia with hydrocele in male and genitalia bleeding in female. The increasing production of sebum also found to be related to stimulation by androgen, marked by the increase of DHEAS plasm level and persisted in the first 3 months of life. High level of androgen in 7 years old is due to increasing production of DHEA-S by adrenal glands and related to puberty. Later, there is a decreased level of DHEA-S in early adolescent and tend to decrease further with age, along with the decrease of sebum production. ${ }^{3,4,10}$

Weaker androgen hormone, dehydroepiandrosterone sulphate (DHEA-S) is a significant stimulating factor of sebaceous glands activities. DHEAS is a significant regulation of sebum production. DHEA-S will be converted into testosterones and $5 \mathrm{a}-\mathrm{DHT}$ in sebaceous glands. This conversion of DHEA-S into both testosterones and 5aDHTs is an enzymatic process under the stimulation of $3 \beta$-hydroxysteroid dehydrogenase, $17 \beta$ - hydroxysteroid dehydrogenase, and 5a-reductase. $3,10,19,20$

In sebaceous glands, both testosterones and 5aDHTs will work after binding to androgen receptors. The bond between 5a-DHTs and androgen receptors is 5 to 10 times stronger than the bound of testosterones and androgen receptors. Androgen receptors is needed to stimulate the differentiation of sebocytes. Peroxisome proliferator-activated receptor (PPAR) is receptors to modulate the differentiation of sebocytes. 4

The production of sebum varies from person to person and race. The production of sebum production 
is relatively stable from puberty to middle aged both in female and male and tend to decrease after adult. In third decade, sebum production decrease about $23 \%$ per decade in male and $32 \%$ per decade in female, along with the decrease of DHEAS serum level. 18

Other hormones that influence the production of androgen and sebum is insulin-like growth factors (IGF)-1 (Figure 4) that sintethyzed in liver with Pituitary's growth hormones stimulation. Later, IGF-1 will influence pilosebaceous unit in IGF1/AKT/mTORC1/SREBP1 signaling pathway and produces androgen hormones and sebum. Insulin-like growth factors- 1 regulates the synthesis of androgen, metabolism of androgen and sensitivity of androgen target organ. IGF-1 induces adrenal and gonadal synthesis of androgens, inducing the expression of $5 a-$ reductase which leads to the increasing level of testosterones conversion into DHTs. Basal and suprabasal sebocytes express IGF-1 receptors. Both androgen and IGF-1 will increase the expression of sebocytes SREBP1c during lipogenesis of sebum. Both insulin and IGF-1 activates mechanistic target of rapamycin complex 1 (mTORC1) and stimulate expression of $\gamma$ and SREBP1c receptors, leading to the increase of sebum production. ${ }^{18}$

Table 1. Concentration of synthesized androgen in blood plasma $(\mathrm{mmol} / \mathrm{l})$ and androgen power in adult 6

\begin{tabular}{lccc}
\hline & Male & Female & Androgen power \\
\hline Dehydroepiandrosterone sulfate & $1300-6800$ & $1300-6800$ & 1 \\
Androstenediones & $3.0-5.0$ & $3.5-7.0$ & 2 \\
Testosterones & $10-35$ & $<3.5$ & 10 \\
5a-dihydrotestosterones & $0.87-2.6$ & $0.17-1.0$ & 60 \\
\hline
\end{tabular}

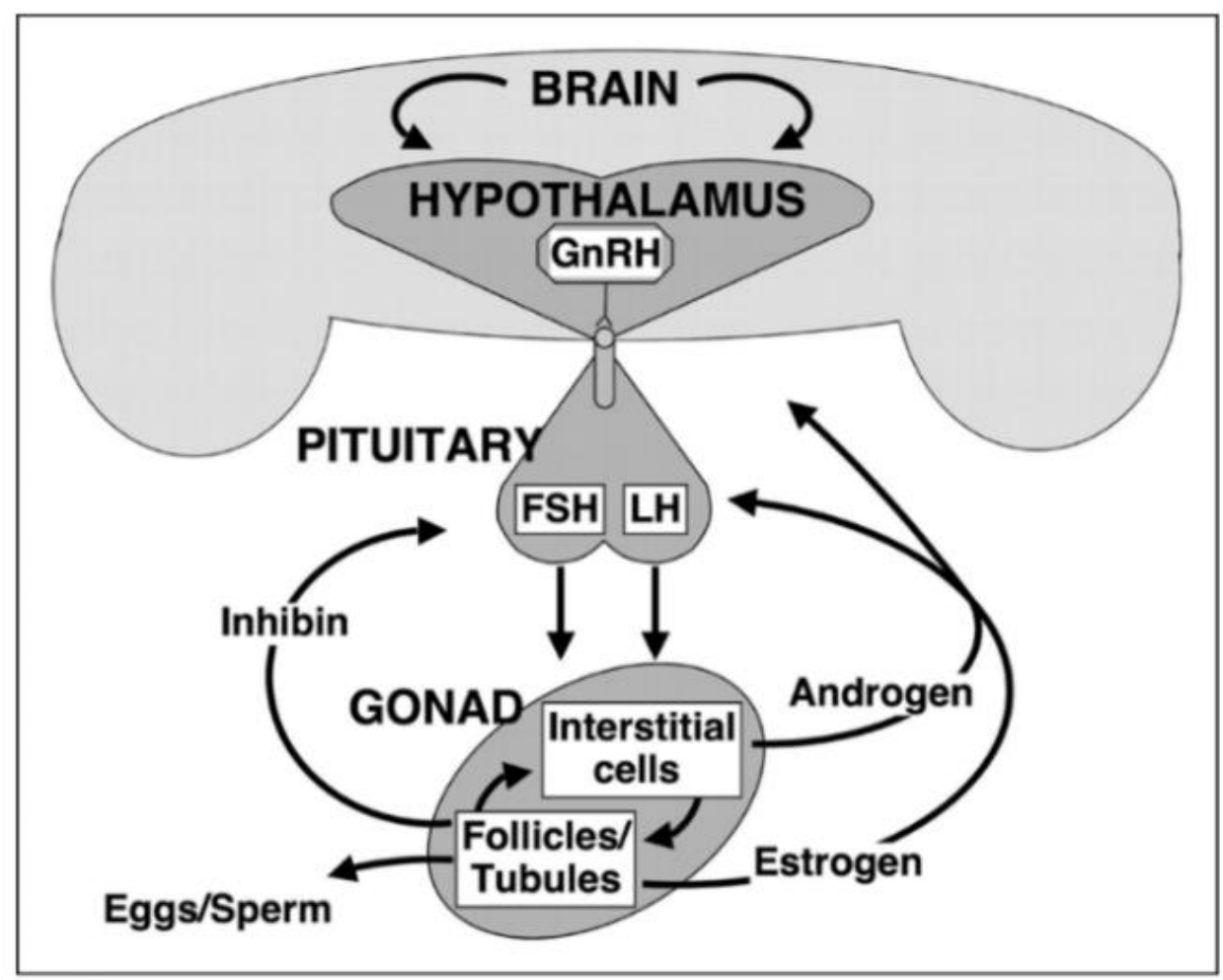

Figure 1. Mechanism of androgens productions ${ }^{5}$ 
Table 2. Enzymes that Activate Androgen on Skin 4

\begin{tabular}{|c|c|}
\hline Enzymes & Activities \\
\hline Steroid sulfatase & Convert DHEA-S to DHEA \\
\hline $3 \beta$-hydroxysteroid dehydrogenase & $\begin{array}{l}\text { - Convert DHEA to androstenedione } \\
\text { - Isoform type } 1 \text { expressed in sebaceous glands and } \\
\text { terminal papilla of human hair }\end{array}$ \\
\hline $\begin{array}{l}17 \beta \text {-hydroxysteroid } \\
\text { dehydrogenase }\end{array}$ & $\begin{array}{l}\text { - Convert androstenedione to testosterone } \\
\text { - Located in pilosebaceous unit and epidermal } \\
\text { keratinocyte } \\
\text { - Some isoforms will increase androgen (reduction) or } \\
\text { decrease androgen (oxidation) }\end{array}$ \\
\hline $5 a-$ reductase & 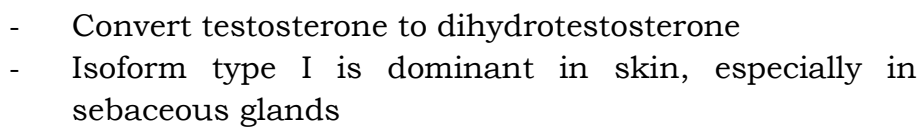 \\
\hline 3a-hydroxysteroid dehydrogenase & $\begin{array}{l}\text { - Catabolize androgen to become unbound-to-androgen } \\
\text { receptor metabolites } \\
\text { - There are } 3 \text { isoforms. }\end{array}$ \\
\hline Aromatase & $\begin{array}{l}\text { - Convert } \mathrm{T} \text { to androstenedione to estrogen in some types } \\
\text { of cells }\end{array}$ \\
\hline
\end{tabular}

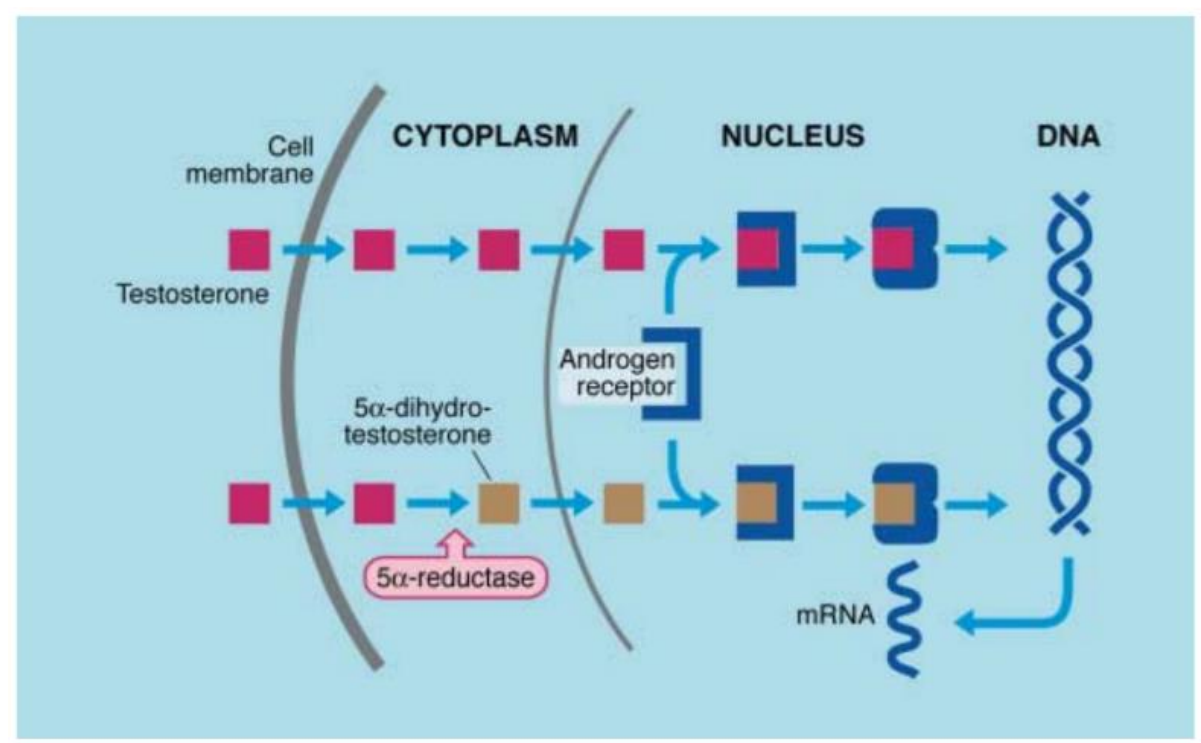

Figure 2. Testosterones and $5 \mathrm{a}-\mathrm{DHT}$ s bind to the androgen receptors 13

Table 3. Location 5a-reductase enzyme ${ }^{17}$

\begin{tabular}{lll}
\multicolumn{1}{c}{ Type 1 } & \multicolumn{1}{c}{ Type 2 } \\
\hline - Transient hair after born & $\bullet$ & Transient hair after born \\
- Permanent hair after puberty & $\bullet \quad$ Permanent hair of scalp and pubic after \\
- Axillary hair follicle & & puberty \\
- Liver & $\bullet$ & Hair follicles of beard \\
- Seminal vesicle & $\bullet$ & Internal and external male genitalia \\
- Ventral of prostate & $\bullet$ & Liver \\
\hline
\end{tabular}




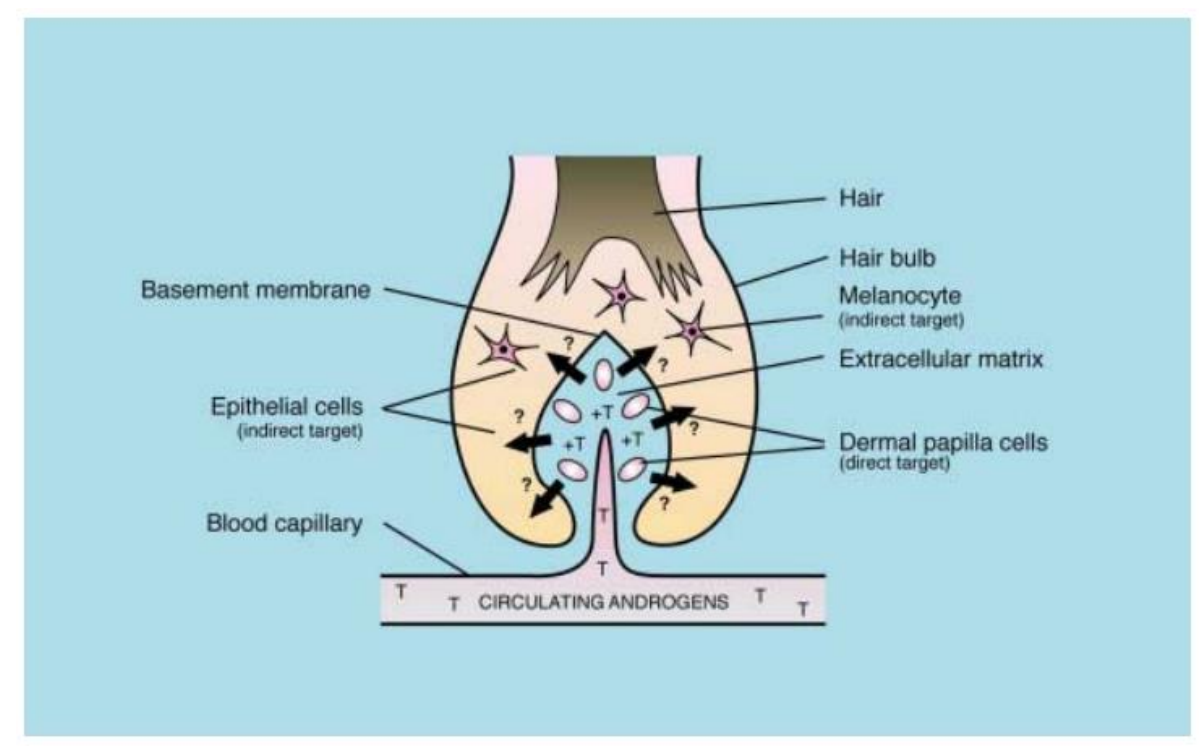

Figure 3. Mechanism of androgen in hair follicles ${ }^{13}$

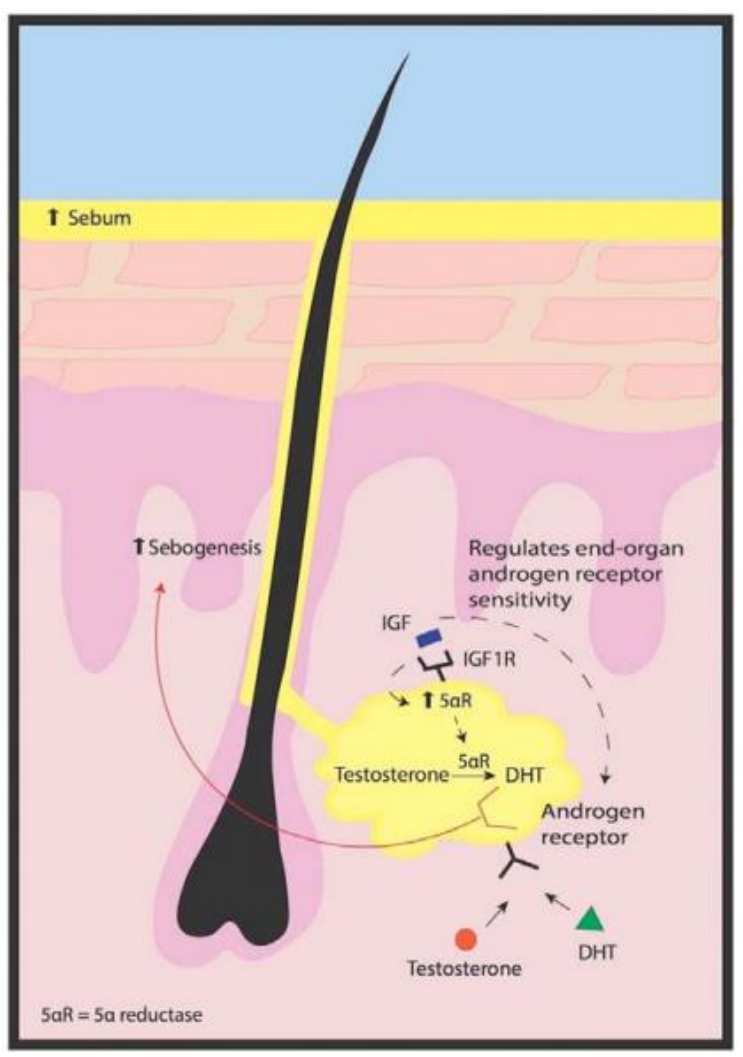

Figure 4. Androgen and pilosebaceous unit 18

\section{Conclusions}

Androgen plays a role in the physiological function of the pilosebaceous unit. Androgen is synthesized in gonad (ovarium and testis), adrenal and skin. The androgen is 10 times higher in male compare to female.
The mechanism of action of androgen depends on their interaction with androgen receptors. Interaction between androgen and androgen receptor in pilosebaceous unit, especially on the dermal papillae of hair follicle, will influence hair growth, while interaction with sebaceous glands (sebocytes) will affect the 
production of sebum. Highly active androgen in pilosebaceous unit are testosterone and 5a- DHT.

\section{References}

1. McGrath1 JA, Uitto J. Structure and Function of the Skin. In: Griffiths CEM, Barker J, Bleiker $\mathrm{T}$, Chalmers R, Creamer D, editors. Rook's Textbook of Dermatology. USA: John Wiley \& Sons, Ltd; 2016.

2. Camacho I, Tzu J, Kirsner RS. The skin as an endocrine target. $\mathrm{J}$ Invest Dermatol. 2010;130(1):6.

3. Zouboulis CC. Skin Glands: Sebaceous, Eccrine, and Apocrine Glands. In: Kang S, Amagai M, Bruckner AL, Enk AH, Margolis DJ, McMichael AJ, et al., editors. Fitzpatrick's Dermatology. 9th ed. New York: McGraw-Hill; 2019. p. 70-88.

4. Del Rosso JQ, Kircik LH, Stein Gold L, Thiboutot D. Androgens, Androgen Receptors, and the Skin: From the Laboratory to the Clinic With Emphasis on Clinical and Therapeutic Implications. J Drugs Dermatol. 2020;19(3):30-5.

5. Bordini B, Rosenfield RL. Normal pubertal development: Part I: The endocrine basis of puberty. Pediatr Rev. 2011;32(6):223-9.

6. Zouboulis CC, Degitz K. Androgen action on human skin - From basic research to clinical significance. Vol. 13, Experimental Dermatology, Supplement. 2004. p. 5-10.

7. Bienenfeld A, Azarchi S, Lo Sicco K, Marchbein S, Shapiro J, Nagler AR. Androgens in women: Androgen-mediated skin disease and patient evaluation. J Am Acad Dermatol. 2019;80(6):1497-506.

8. Azzouni F, Godoy A, Li Y, Mohler J. The 5 alpha-reductase isozyme family: A review of basic biology and their role in human diseases. Adv Urol. 2012;2012.

9. Inui $\mathrm{S}$, Itami $\mathrm{S}$. Androgen actions on the human hair follicle: Perspectives. Exp Dermatol. 2013;22(3):168-71.
10. Ceruti JM, Leirós GJ, Balañá ME. Androgens and androgen receptor action in skin and hair follicles. Mol Cell Endocrinol. 2018;465:12233.

11. Grymowicz M, Rudnicka E, Podfigurna A, Napierala P, Smolarczyk R, Smolarczyk K, et al. Hormonal effects on hair follicles. Int J Mol Sci. 2020;21(15):1-13.

12. Patrão MTCC, Silva EJR, Avellar MCW. Androgens and the male reproductive tract: an overview of classical roles and current perspectives. Arq Bras Endocrinol Metabol. 2009;53(8):934-45.

13. Randall VA. Androgens and hair growth. Dermatol Ther. 2008;21:314-28.

14. Durdiakova J, Ostatnikova D, Celec P. Testosterone and its metabolites - modulators of brain functions. Acta Neurobiol Exp (Wars). 2011;71(4):434-54.

15. Brinkmann AO. Molecular basis of androgen insensitivity. Mol Cell Endocrinol. 2001;179(12):105-9.

16. Messenger AG, Sinclair RD, Farrant P, Berker DAR de. Acquired Disorders of Hair. In: Chalmers R, Barker J, Griffiths C, Bleiker T, Creamer D, editors. Rook's Textbook of Dermatology. 9th ed. New Delhi: John Wiley \& Sons; 2016.

17. Marchetti PM, Barth JH. Clinical biochemistry of dihydrotestosterone. Ann Clin Biochem. 2013;50(2):95-107.

18. Saric-Bosanac S, Clark AK, Sivamani RK, Shi VY. The role of hypothalamus-pituitaryadrenal (HPA)-like axis in inflammatory pilosebaceous disorders. Dermatol Online J. 2020;26(2).

19. Makrantonaki E, Ganceviciene R, Zouboulis C. An update on the role of the sebaceous gland in the pathogenesis of acne. Dermatoendocrinol. 2011;3(1):41-9.

20. Clarke SB, Nelson AM, George RE, Thiboutot DM. Pharmacologic Modulation of Sebaceous Gland Activity: Mechanisms and Clinical Applications. 2007;25:137-46. 